\title{
The Assemblage Betwixt Mango Assessment Concatenation Breakdown And The Commercial Encouragement
}

\author{
Prof. Syed Makena, Prof. Raheleh Kashanian
}

Faculty Of Agriculture Food Security And Biodiversity, Nairobi University, Kenya

\begin{abstract}
The study targeted on a price concatenation breakdown meshed towards distinctive the assorted, processes, inputs and major players within the mango worth concatenation system. knowledge was collected from the most actors within the mango worth concatenation at totally different segments together with input suppliers, producers, traders and customers employing a structured form. The sampling technique utilized enclosed stratification of respondents on the idea of useful roles of the assorted actors followed by a successive random sample of the requisite range of respondents per section. knowledge and data collected were clean and coded for electronic entry and analysis. The applied Math Package for Social Sciences (MPSS) and Microsoft surpass were utilized come back up with\} basic descriptive statistics together with frequencies, percentages, z-scores, chi-squares, normal deviations and minimum and most levels in addition because the means that. These were accustomed organize the info for thorough breakdown and presentation. Results showed that vital commercial encouragement of the useful roles of actors within the numerous mango concatenation segments enclosed financial gain, education, age, gender, farm size or size of business operation. These variables influence the factory farm uptake pathways impended in mango worth concatenation and so their importance in policy formulation and technology recommendation domains.
\end{abstract}

Key Words: Analysis, Determinants, Constrains, Mango, Socio-economic, worth Chain 


\section{ENGINEERING}

\section{Introduction}

As a sector in Agriculture and therefore the larger economy of the country, agriculture contributes vastly to economic process, supply of financial gain to smallholders, improved nutritionary standing and a serious interchange jobholder. an summary of the agriculture subsector in Kenya shows that the world includes in the main of fruits, vegetables and cut flowers. The sub-sector accounts for concerning ten \% of urban food consumption and a far larger proportion in rural areas. consistent with Food and Agriculture Organization of the United Nations (2018), vegetables dominate agriculture production, followed by fruits and cut flowers.

This study was sponsored by set up International with the motivation of distinctive agricultural enterprises with a possible within the study space and perform a price concatenation breakdown to isolate the constraints that inhibit profitableness and scaling up. The study was to create the inspiration for distinctive and reviewing of the required mango market interventions, coaching wants, potential demand driven market infrastructure investments, evaluating requests for programme support, and providing support to extend the potency of natural mango market evolution that has positive impact on the agricultural community livelihoods. Mango was known together with four others commodities i.e. sunflower, fish farming, native poultry and bee keeping as agricultural enterprises that have the best potential to function a vehicle for financial condition reduction and supply of bread and butter for a majority of farmer farmers and traders within the project areas.

In the 1st place a good worth concatenation breakdown approach would facilitate within the identification of fine policies and programmes to accelerate development and this needs a decent understanding of however native enterprises work into the worldwide economy. Secondly, the approach would helps to spot and choose relevant stakeholders for programme coming up with, together with distant consumers wherever they exert robust influence over the chain. 


\section{THE AMERICAN JOURNAL OF}

AGRICULTURE AND BIOMEDICAL

VOLUME01 ISSUE05

\section{ENGINEERING}

\section{Materials and ways}

Study style The study started with a desktop review of trends in production, marketed volume, artifact and gross margins for the mango commodities within the city West District in addition as relevant literature and publications on assessment concatenation analysis. The desktop review was followed by advisory conferences with the city set up International workers and therefore the line Ministry District technical team. A 2 day democratic coaching for the enumerators was conducted involving the utilization of the study tool and pilot testing of the instrument.

\section{Sampling technique}

The 2 divisions within the district specifically Maseno and Kombewa were clustered into locations and stratified by mango production and promoting concentrations. Sixty sixty farmers, seven input suppliers, twenty three traders and Farmer/traders were interviewed for a complete of 118 respondents within the division from the three locations known for the study. In Kombewa division, four locations were designated supported the concentration of mango production and promoting. Sixty four (64) farmers, five input suppliers, forty two traders and twenty one farmer/traders were targeted for a complete of 132 respondents within the division.

\section{Results and Discussion}

\section{Mango worth Concatenation Mapping}

The main actors within the mango worth concatenation in city West District were: Input Suppliers, Producers, Brokers, Traders (Wholesalers, Retailers and Mobile traders) and customers. Personal interviews and discussions with these actors indicated that there was numerous service suppliers concerned within the worth concatenation map. but it had been 


\section{THE AMERICAN JOURNAL OF}

AGRICULTURE AND BIOMEDICAL

VOLUME01 ISSUE05

\section{ENGINEERING}

determined that the bulk of the service suppliers failed to have a robust presence on the bottom. the key channels within the mango sub-sector within the district enclosed contemporary sale of mango at the farm gate, direct home consumption and sales to traders WHO successively sell the turn out within the market. In terms of volume movement within the worth chain, individual interviews with producers and traders showed that concerning half-hour for home consumption, fifty four was oversubscribed to brokers, and Sixteen Personality Factor Questionnaire was thought of as wastage.

\section{Conclusion and suggestions}

On the idea of information analyzed, it had been complete that the majority actors within the mango worth concatenation had low level of education that hamper new agricultural technology adoption notably those requiring sourcing and decoding info.

Women dominated the retail market section of the mango worth concatenation within the district whereas men had associate favourable position within the production section implying gender inequality within the numerous segments. As a whole, among all the opposite Actors within the mango worth concatenation in city West district, the gender inequality was titled towards the male respondents. this implies that interventions targeting feminine Actors would solely be confined to traders wherever feminine respondents were the bulk within the mango chain. 